\title{
Article \\ Study on Corrosion Behavior of Waterborne Polyurethane Coating with High Thermal Conductivity
}

\author{
Pan Yi ${ }^{1, *}$, Juan Mo ${ }^{1}$, Rui Liu ${ }^{1}$, Baozhen Fan ${ }^{1}$, Kui Xiao ${ }^{2}$, Jin Gao ${ }^{2}$ and Haifei Zhou ${ }^{3}$ \\ 1 China Electric Power Research Institute, Beijing 100192, China; mojuan@epri.sgcc.com.cn (J.M.); \\ liurui@epri.sgcc.com.cn (R.L.); fbz@epri.sgcc.com.cn (B.F.) \\ 2 Institute for Advanced Materials and Technology, University of Science and Technology Beijing, \\ Beijing 100083, China; xiaokui@sina.com (K.X.); gaojin@ustb.edu.cn (J.G.) \\ 3 Zhejiang Electric Power Corporation Research Institute, Hangzhou 310014, China; zhouhf@alum.imr.ac.cn \\ * Correspondence: bkyipan@126.com
}

check for updates

Citation: Yi, P.; Mo, J.; Liu, R.; Fan, B.; Xiao, K.; Gao, J.; Zhou, H. Study on Corrosion Behavior of Waterborne Polyurethane Coating with High Thermal Conductivity. Appl. Sci. 2022, 12, 2021. https://doi.org/ 10.3390/app12042021

Academic Editor: Frank Walther

Received: 18 January 2022

Accepted: 11 February 2022

Published: 15 February 2022

Publisher's Note: MDPI stays neutral with regard to jurisdictional claims in published maps and institutional affiliations.

Copyright: () 2022 by the authors Licensee MDPI, Basel, Switzerland. This article is an open access article distributed under the terms and conditions of the Creative Commons Attribution (CC BY) license (https:// creativecommons.org/licenses/by/ $4.0 /)$.

\begin{abstract}
In this paper, the effects of mixture fillers on the thermal conductivity of a coating are studied, and the optimal addition proportion was obtained. Then, the corrosion behavior of the modified waterborne polyurethane coating with high thermal conductivity is investigated by salt spray experiments, pull-off tests, EIS and SKP measurements. The result shows that the coating with $2 \mathrm{wt} \%$ composite fillers exhibits the most excellent thermal conductivity $\left(1.222 \mathrm{~W} \cdot \mathrm{m}^{-1} \cdot \mathrm{K}^{-1}\right)$. In terms of corrosion resistance, there is an absence of obvious corrosion phenomenon for the modified coating, and the polarization resistance is still as high as $1.31 \times 10^{7} \Omega \cdot \mathrm{cm}^{2}$ at the final stage, which indicates that the incorporation of $2 \mathrm{wt} \%$ composite fillers also markedly enhances the corrosion resistance property of waterborne polyurethane coating. This is mainly attributed to the more compact structure and more excellent shielding action to the electrolyte. The surface Kelvin potential results further confirm the advantageous effects of mixture fillers on the corrosion protective performance. The corresponding protective mechanism of the composite coating is also proposed.
\end{abstract}

Keywords: waterborne polyurethane coating; corrosion; high thermal conductivity coating; SKP

\section{Introduction}

With the rapid development of the power industry, the service scope of power transmission and transformation equipment gradually expands, even including the high salt spray, heavy sand, and strong sunshine environment. In this situation, the corrosion reliability problem is particularly prominent [1]. For the power equipment, such as transformers, some coatings are generally used to improve their corrosion resistance and extend the service life. However, it is noteworthy that the majority of currently commonly used coatings are solvent-based products. The emission content of volatile organic compounds (VOCs) of these coatings is around 300-500 g/L, which seriously endangers human health and regional ecological environment safety [2]. Thus, the environmentally friendly anticorrosive coating is the current main trend. Among them, the waterborne anticorrosive coating, such as waterborne polyurethane, has recently obtained increasing attention due to the low VOCs emissions [3,4].

In terms of transformers, in addition to corrosion reliability during service, they usually also face serious temperature rise problems $[5,6]$. The too high hot-spot temperature will accelerate the aging process of the insulation and markedly decrease the transformers' life expectancy $[7,8]$. The waterborne coating promotes the environmental protection performance of anticorrosive coatings for transformers; however, their thermal conductivity is still poor, which cannot meet the heat dissipation requirement of the transformer. Especially for high-power transformers serving in the tropical climate, the over-heating faults frequently occur. Based on this situation, apparently, it is very necessary and urgent 
to develop a new type of low pollution, high thermal conductivity anti-corrosion coating for the power industry protection field.

On the aspect of improving the thermal conductivity of the coating, adding fillers with high thermal conductivity to the matrix is a convenient and effective method [9-11]. Kochetov [12] et al. studied the thermal behavior of epoxy resin added with AlN and BN, and the results showed that the AlN-filled coating exhibited a higher thermal conductivity than BN composites. Compared with the blank sample $(0.168 \mathrm{~W} / \mathrm{m} \cdot \mathrm{K})$, the thermal conductivity of the coating with $10 \mathrm{wt} \% \mathrm{AlN}$ reached $0.1987 \mathrm{~W} / \mathrm{m} \cdot \mathrm{K}$. Bian [13] et al. reported the synergistic effects of the $\mathrm{BN}$ and $\mathrm{Al}_{2} \mathrm{O}_{3}$ on enhancing the thermal conductivity of epoxy resin, and it was found that a composite with high thermal conductivity of $1.182 \mathrm{~W} / \mathrm{m} \cdot \mathrm{K}$ was obtained after adding $22.5 \mathrm{wt} \% \mathrm{BN}$ and $7.5 \mathrm{wt} \% \mathrm{Al}_{2} \mathrm{O}_{3}$. In addition to these inorganic additives, the graphene and carbon nanotubes gained the increasing attention from academic and industrial fields due to its excellent thermal conductivity properties and good compatibility with polymer matrix $[3,14]$. Shi $[15]$ et al. investigated the effects of graphene/carbon nanotube on the thermal conductivity of acrylic resin. They concluded that the coating modified with $9.9 \mathrm{wt} \%$ graphene nanosheets and $0.1 \mathrm{wt} \%$ carbon nanotubes displayed a high thermal conductivity of $2.97 \mathrm{~W} / \mathrm{m} \cdot \mathrm{K}$, which is related to the formation of honeycomb structure and decreasing of the interface heat resistance. Obviously, carbon nanomaterials show great advantages in improving the thermal conductivity of coatings.

It is noteworthy that the expense of the graphene and carbon nanotubes is very high, and the dispersion process of single-component graphene in coatings is very difficult and usually needs some pre-processing technology [16], which greatly limits the application of graphene coatings in the power industry. Considering the above situations, exploring a low-cost coating with high thermal conductivity is of great significance for engineering applications. In this paper, a low-cost commercial mixture of carbon nanotubes, carbon nanohorns, graphene, and ultrafine graphite powder is used to modify the thermal conductivity of waterborne polyurethane coating. Subsequently, the thermal conductivity and corrosion resistance performance are evaluated through the plate heat source method and salt spray experiment, respectively. Electrochemical impedance spectroscopy (EIS) and the scanning Kelvin probe (SKP) technique are used to analyze the corrosion failure mechanism of modified waterborne polyurethane coating.

\section{Materials and Methods}

\subsection{Preparation of Coating}

In this paper, the waterborne polyurethane coating is the raw material. The commercial mixture of carbon nanotubes, carbon nanohorns, graphene, and ultrafine graphite powder is added into polyurethane coating to modify the thermal conductivity. Figure 1 shows the topography characteristics of composite fillers. It can be seen that it includes flakes, rods, and granular substances. According to the previously published literature [15], the composites consisted of different size and shape substance could closely contact and form honeycomb structure in coating and thus cause the synergistic effects for the improvement of thermal conductivity properties. The addition ratio ranges from $1 \mathrm{wt} \%$ to $6 \mathrm{wt} \%$. The titanium dioxide is used to adjust the paint color so that it appears as a sea gray B05 color. During the preparation of coating samples, the polyurethane curing agent is added firstly to the modified high thermal conductivity coating in a ratio of 1:5. Then, the modified coating is brushed on the surface of the Q235 sample with a roughness of Sa2.5. After the coating surface is dry, the coating thickness is tested using a coating thickness gauge. Ensure that the dry film thickness is around $100 \mu \mathrm{m}$ by adjusting the number of brushing. After the modified coating is fully cured, the corrosion experiments are carried out. Moreover, the coating was cured as a square with a thickness of about $5 \mathrm{~mm}$ for thermal conductivity testing. 


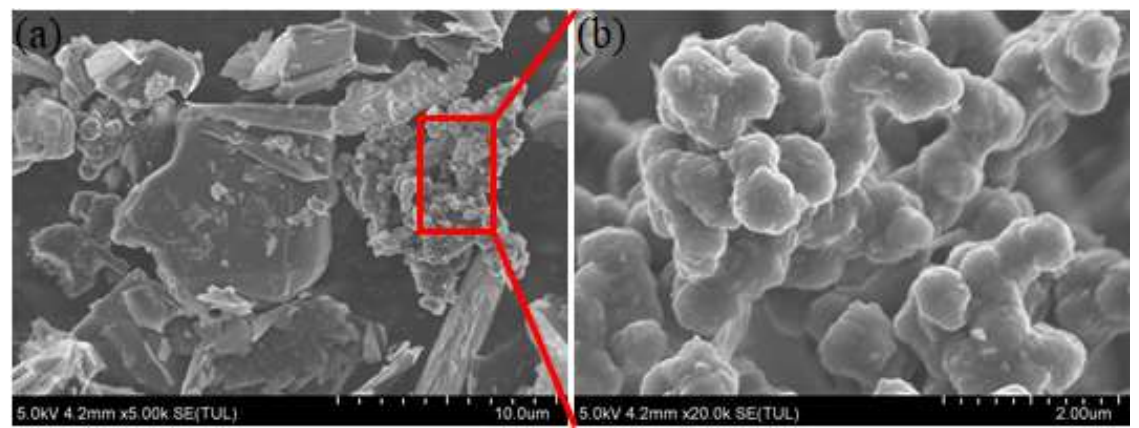

Figure 1. The topography of the mixture fillers (a) and the magnification picture of the red triangle box region $(\mathbf{b})$.

\subsection{Thermal Conductivity Measurement}

The effects of filler on the thermal conductivity of waterborne polyurethane coating are characterized by the plate heat source method. The thermal conductivity instrument (C-Therm TCi, Fredericton, NB, Canada) is employed during these tests, and the test temperature is $40^{\circ} \mathrm{C}$. To ensure the reproducibility, the thermal conductivity measurement was repeated three times at least.

\subsection{Salt Spray Experiment}

To observe the corrosion resistance of the composites coating, the salt spray test is conducted according to the standard GB/T 1771-2007. The test specimens include complete specimens and crossed specimens. The concentration of $\mathrm{NaCl}$ solution prepared by analytical pure $\mathrm{NaCl}$ and deionized water is $5 \mathrm{wt} \%$. The experimental temperature is $35^{\circ} \mathrm{C}$. This salt spray test cycles are 3 day (d), $6 \mathrm{~d}$, and $10 \mathrm{~d}$. After the salt spray test, the corrosion topography is observed, and the adhesion strength is obtained through the pull-off test.

\subsection{EIS Measurement}

After the salt spray experiment, an EIS test is carried out using a traditional threeelectrode system and a CS410 electrochemical workstation. A platinum plate and saturated calomel electrode (SCE) function as the counter electrode and reference electrode, respectively. The area of the working electrode is $0.785 \mathrm{~cm}^{2}$. A $3.5 \mathrm{wt} \% \mathrm{NaCl}$ solution is used as an electrolyte of the EIS test. The measuring frequency ranges from $100 \mathrm{kHz}$ to $10 \mathrm{mHz}$, using a perturbation of $10 \mathrm{mV}$. After the electrochemical tests, Zsimpwin 3.50 software is used to fit the EIS data.

\subsection{SKP Measurement}

The Kelvin potential of a coating sample surface was measured using an M370 electrochemical workstation with a work distance of $150 \pm 5 \mu \mathrm{m}$. The test area is $3000 \mu \mathrm{m} \times 500 \mu \mathrm{m}$, and the step size is $50 \mu \mathrm{m}$. All experiments were conducted in a stable laboratory environment at $20{ }^{\circ} \mathrm{C}$ and $50 \% \mathrm{RH}$.

\section{Results and Discussion}

\subsection{Thermal Conductivity}

Figure 2 shows the thermal conductivity results of the waterborne polyurethane coating with different proportions of high thermal conductivity filler. Obviously, the waterborne polyurethane coating displays a very low thermal conductivity, and it is $0.1638 \mathrm{~W} /(\mathrm{m} \cdot \mathrm{K})$. When the composites fillers are added into the waterborne polyurethane coating, the thermal conductivity markedly increases. Especially for modified coating with the $2 \mathrm{wt} \%$ fillers, the thermal conductivity is up to $1.222 \mathrm{~W} /(\mathrm{m} \cdot \mathrm{K})$, which is higher than the previously reported results $[17,18]$. It may be attributed to the synergistic effect of different composite in fillers. As the addition amount of fillers continues to increase, the thermal conductivity 
has a slight decreasing trend, which may be related to the titanium dioxide added during the toning process. Overall, this result indicates that the composites fillers can be used to significantly enhance the thermal conductivity of the waterborne polyurethane coating, which is beneficial for improving the heat dissipation performance of the transformer. Subsequently, to observe the corrosion protection performance of the modified coating in the corrosive atmospheric environment, the salt spray experiment is conducted for the coating with $2 \mathrm{wt} \%$ fillers.

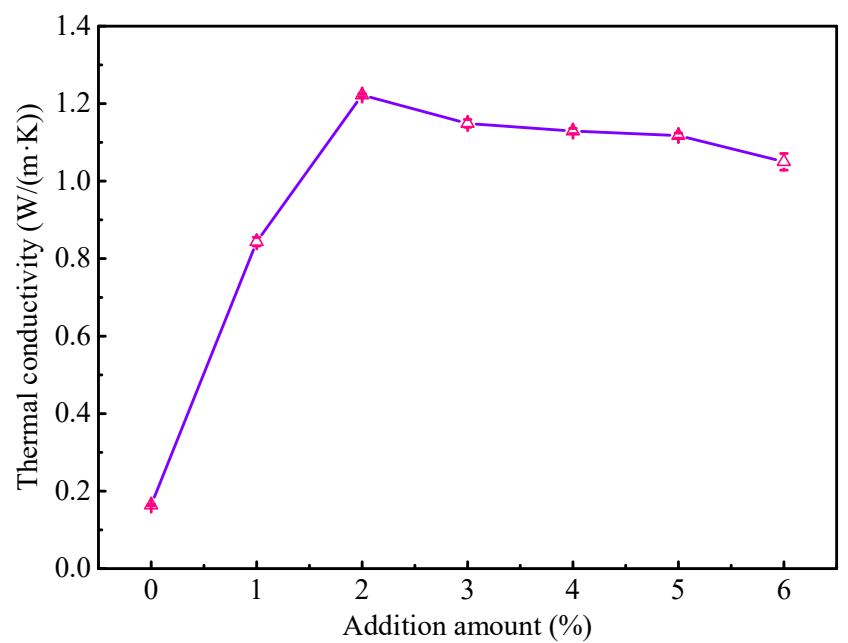

Figure 2. The thermal conductivity results of waterborne polyurethane coating.

\subsection{Topography Observation}

The corrosion protection performance of the waterborne polyurethane coating with the best thermal conductivity is evaluated through salt spray experiments. Figure 3 shows the surface topography of the samples after the salt spray test. It can be seen that the sample surface before the salt spray test is flat and depicts a sea gray color. After $6 \mathrm{~d}$ of salt spray tests, there are some rust spots on the surface of the sample without a composite filler (Figure 3g). As time elapses, the rust spots evidently increase (Figure 3h), which suggests that the corrosive ions have penetrated into the substrate, causing corrosion of the substrate metal. In this case, the formed iron cations and iron oxides will diffuse outward [19], which will further damage the coating's resistance to penetration and reduce its protective performance. However, for the coating with $2 \mathrm{wt} \%$ composites filler, the coating surface displays no apparent rust spots and blisters at the full stage of salt spray tests, suggesting that the modified coating can provide excellent protection performance.

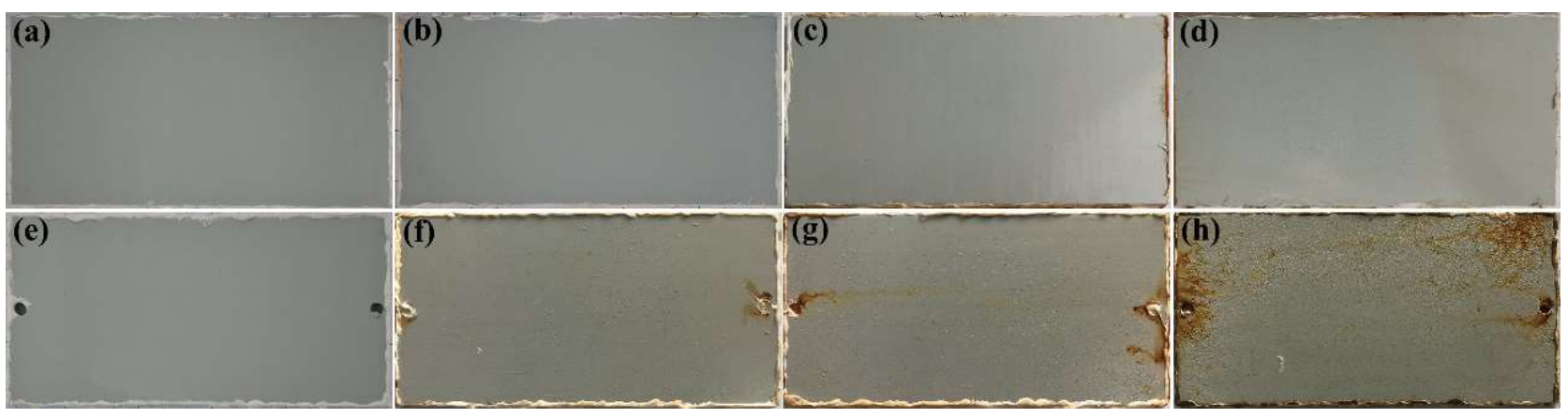

Figure 3. The surface topography of the samples at different period of salt spray test; (a-d) the topography of the coating with composites fillers after $0 \mathrm{~d}, 3 \mathrm{~d}, 6 \mathrm{~d}$, and $10 \mathrm{~d}$, respectively; (e-h) the topography of the coating without fillers after $0 \mathrm{~d}, 3 \mathrm{~d}, 6 \mathrm{~d}$, and $10 \mathrm{~d}$, respectively.

Considering the importance of the coating adhesion for the service reliability, the adhesion strength of the modified coating with $2 \mathrm{wt} \%$ fillers is tested by the pull-off test, 
as shown in Figure 4. The initial adhesion strength of the modified coating is around $12 \mathrm{Mpa}$, which approaches the value of the similar waterborne polyurethane coating in the previously published study [20]. As the salt spray time extends, the coating adhesion strength gradually decreases due to the infiltration of electrolyte. After $10 \mathrm{~d}$ of salt spray tests, it is still up to $8.5 \mathrm{Mpa}$, indicating that the modified coating greatly inhibits the penetration of the corrosive ions, which is a basis for the superior anticorrosion performance of coating.

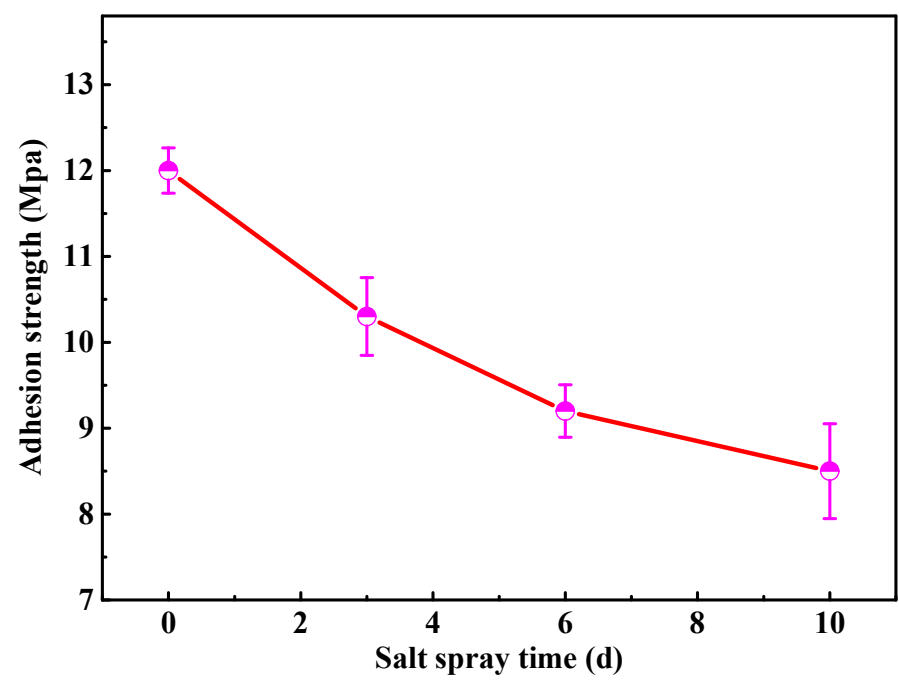

Figure 4. The adhesion strength of the modified waterborne polyurethane coating.

\subsection{EIS Results and Analysis}

To further study the effects of composites filler on the corrosion resistance of waterborne polyurethane coating, the EIS diagram is obtained in $3.5 \mathrm{wt} \% \mathrm{NaCl}$ solution, as is shown in Figure 5. Generally, larger capacitive arcs and diameters of the Nyquist diagram denote much better protective performance [21,22]. In the case of a waterborne polyurethane coating (Figure 5a), the diameter of capacitive arcs depicts a drastic downtrend as the salt spray time extends, indicating the rapid decline of the protective performance for the substrate. Two time constants are observed in this period, representing that the corrosion reactions start at the interface between the substrate and coating. After $10 \mathrm{~d}$ of salt spray tests, the sample suffers from severe corrosion damage (Figure $3 \mathrm{~h}$ ), and a lot of yellow rust emerges on the sample surface. The capacitive arc significantly decreases (Figure 5a). For the modified coating with $2 \mathrm{wt} \%$ composites filler, the diameter of the capacitive arcs in the Nyquist diagram (Figure 5c) is clearly larger than it in Figure 5a, indicating that the modified coating possesses more excellent anti-permeability to the corrosive medium.

The modulus value of the impedance $\left(\mid \mathrm{ZI} \mathrm{I}_{0.01 \mathrm{~Hz}}\right)$ at the low frequency $(0.01 \mathrm{~Hz})$ can be used for evaluating the impermeable and shielding properties of the coating [23,24]. Obviously, the $|Z|_{0.01 \mathrm{~Hz}}$ of the waterborne polyurethane coating gradually declines from $2.85 \times 10^{7} \Omega \cdot \mathrm{cm}^{2}$ to $3.24 \times 10^{4} \Omega \cdot \mathrm{cm}^{2}$ (Figure $5 \mathrm{~b}$ ) with the extension of the salt spray time, suggesting that this coating has almost already lost the role of shielding electrolytes. In comparison, the coating samples with $2 \mathrm{wt} \%$ composites filler display the higher impedance modulus at $0.01 \mathrm{~Hz}$ during the entire salt spray test stage, and the $|\mathrm{Z}|_{0.01 \mathrm{~Hz}}$ value of modified coating is still up to $1.31 \times 10^{7} \Omega \cdot \mathrm{cm}^{2}$ after $10 \mathrm{~d}$ of salt spray tests. These results demonstrate that the modified coating can provide more excellent protective capability for the substrate steel.

The EIS results are fitted for further elaborating the protective mechanism of the modified coating by Zsimpwin software. The equivalent circuit in Figure 6a is used to fit the EIS data of the coating samples. For the EIS curve of coating without a composite filler after $10 \mathrm{~d}$ of the salt spray experiment, the equivalent circuit in Figure $6 \mathrm{~b}$ is employed 
due to the obstruction effects from the rust layer to the ions [25,26]. In the equivalent circuit, $R_{\mathrm{S}}$ is the solution resistance, while $C P E_{\mathrm{C}}$ and $R_{\mathrm{c}}$ represent the coating capacitance and pore resistance, respectively. $C P E_{\mathrm{dl}}$ and $R_{\mathrm{ct}}$ correspond to the double-layer capacitance and charge transfer resistance. $Z_{\mathrm{W}}$ depicts the Warburg resistance caused by the diffusion process in the electrochemical reaction.
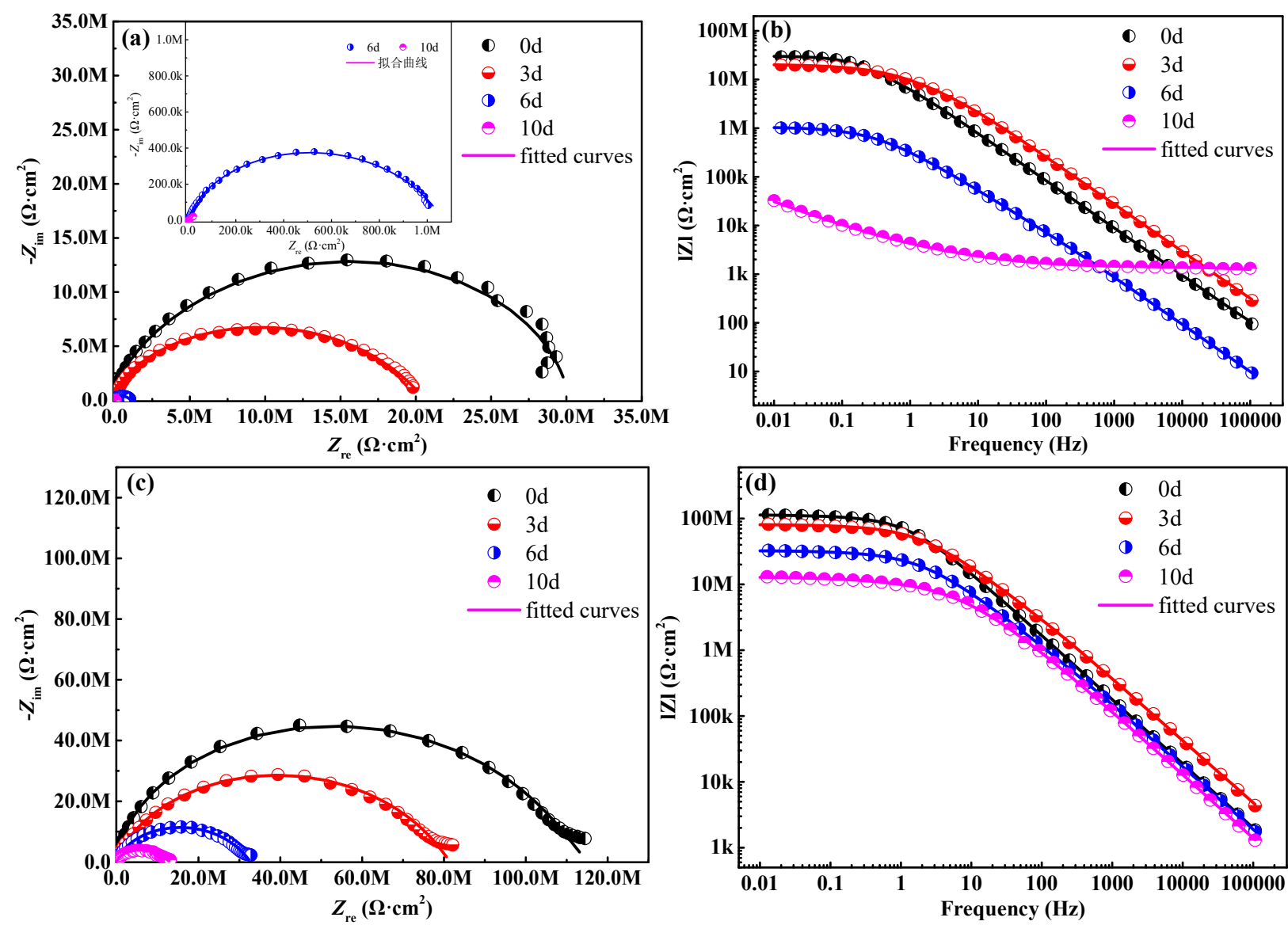

Figure 5. Nyquist and Bode curves of the coating sample, $(\mathbf{a}, \mathbf{b})$ the coating without composites filler, $(\mathbf{c}, \mathbf{d})$ the coating with $2 \mathrm{wt} \%$ composites filler.

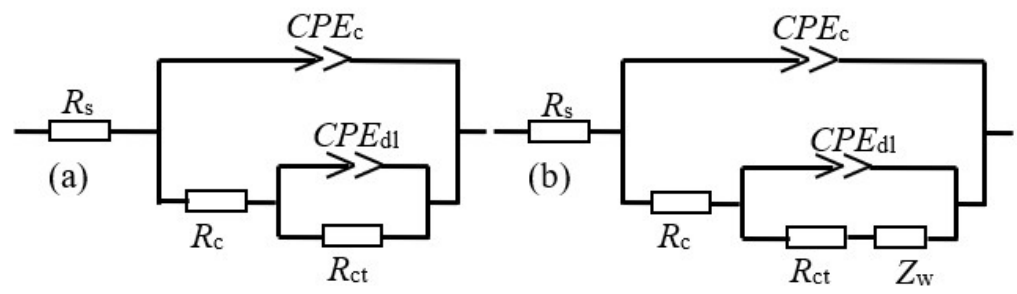

Figure 6. The equivalent electrical circuit for the coating samples in different stages.

The polarization resistance $R_{\mathrm{p}}\left(R_{\mathrm{p}}=R_{\mathrm{c}}+R_{\mathrm{ct}}\right)$ can be used to present the corrosion protective performance of the coating $[27,28]$. In general, the higher $R_{\mathrm{p}}$ value represents a much better corrosion resistance property. Figure 7 depicts the change trend of $R_{\mathrm{p}}$ of the coating at different stages of the salt spray test. Overall, the $R_{\mathrm{p}}$ value of the coating without composite filler shows a decreasing trend with the lengthening of salt spray time. Especially for the sample after $10 \mathrm{~d}$ of salt spray tests, $R_{\mathrm{p}}$ decreases to $3.24 \times 10^{3} \Omega \cdot \mathrm{cm}^{2}$. In this case, the protection function of the polyurethane coating is nearly ineffective. In the meantime, the corrosive ions penetrate into the interface between the coating and substrate metal and result in the severe corrosion process, which is also confirmed by the topography in Figure $3 \mathrm{~h}$. It is noteworthy that for the coating with $2 \mathrm{wt} \%$ composite fillers, the $R_{\mathrm{p}}$ value 
is around $1.15 \times 10^{8} \Omega \cdot \mathrm{cm}^{2}$, which is an order of magnitude larger than that of the coating without mixture fillers. Similarly, as the salt spray time further increases, the $R_{\mathrm{p}}$ value also shows a downtrend due to the infiltration effects of electrolyte. However, it is still up to $1.31 \times 10^{7} \Omega \cdot \mathrm{cm}^{2}$ for the samples that underwent $10 \mathrm{~d}$ of salt spray tests, implying that the modified coating still has a good physical barrier and anticorrosion capability. In addition, the literature reported that the addition of carbon materials (carbon nanotubes, carbon nanohorns, graphene, etc.) could enhance the hydrophobicity of coating, which will further impede the penetration process of aggressive medium and promote anticorrosion effects [29].

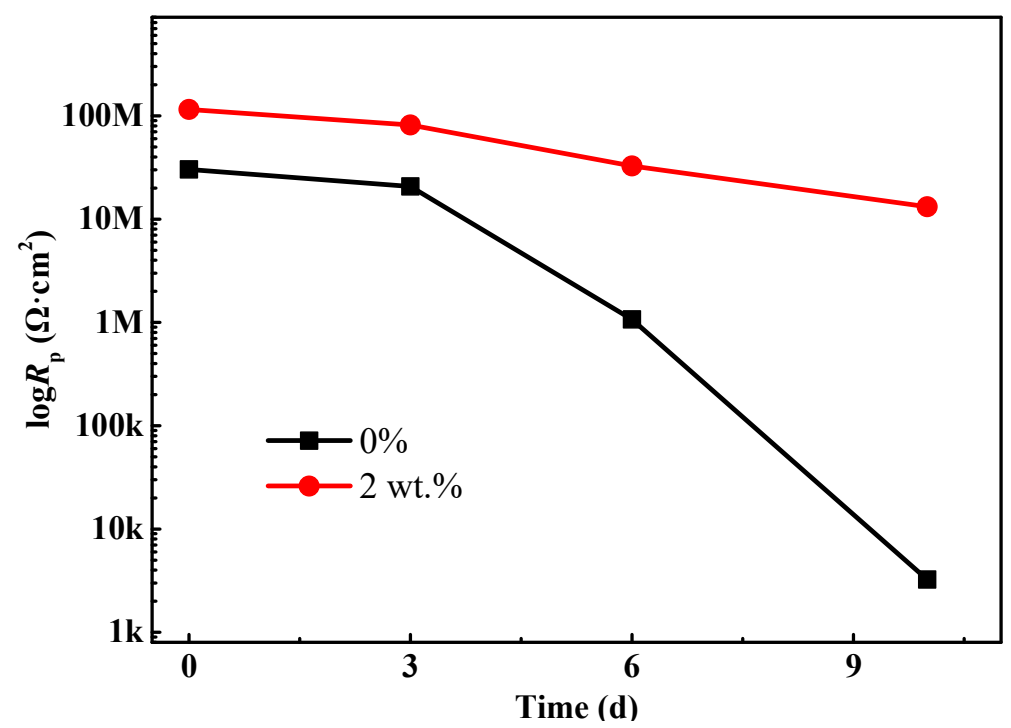

Figure 7. The change trend of the polarization resistance $\left(R_{\mathrm{p}}\right)$ of the waterborne polyurethane coating.

The coating porosity $(P)$ directly affects the shielding properties and the penetration behavior of the electrolyte. It can be calculated according to Equation (1) [30,31], where $R_{\mathrm{pt}}$ represents the coating resistance when the porosity of the coating tends to infinity. It can be obtained through Equation (2). Here, $d(\mu \mathrm{m})$ is the coating thickness. $A\left(\mathrm{~cm}^{2}\right)$ describes the sample area. $k_{0}$ is the electric conductivity of the electrolyte. For the $3.5 \mathrm{wt} \% \mathrm{NaCl}$ solution, it is around $3 \mathrm{~S} / \mathrm{m}$.

$$
\begin{aligned}
P & =\frac{R_{\mathrm{pt}}}{R_{\mathrm{c}}} \\
R_{\mathrm{pt}} & =\frac{0.01 d}{A \cdot k_{0}}
\end{aligned}
$$

Figure 8 displays the change trend of coating porosity with the salt spray time. It can be found that the coating porosity gradually increases with the increasing of salt spray time. Overall, the porosity of the modified coating with $2 \mathrm{wt} \%$ fillers is lower than that of the blank coating, implying that composite fillers can improve the compactness of coating and enhance the shielding property to the electrolyte. Moreover, as the salt spray test time extends, the porosity of the blank sample markedly increases, while it still remains at a low level for the modified coating sample. This phenomenon is attributed to the severe corrosion caused by penetration of an electrolyte. In comparison, there is an absence of obvious corrosion for the modified coating sample, which is verified by the topography in Figure $3 \mathrm{~d}$. Thus, the modified coating sample still retains excellent protective performance after $10 \mathrm{~d}$ of salt spray tests. 


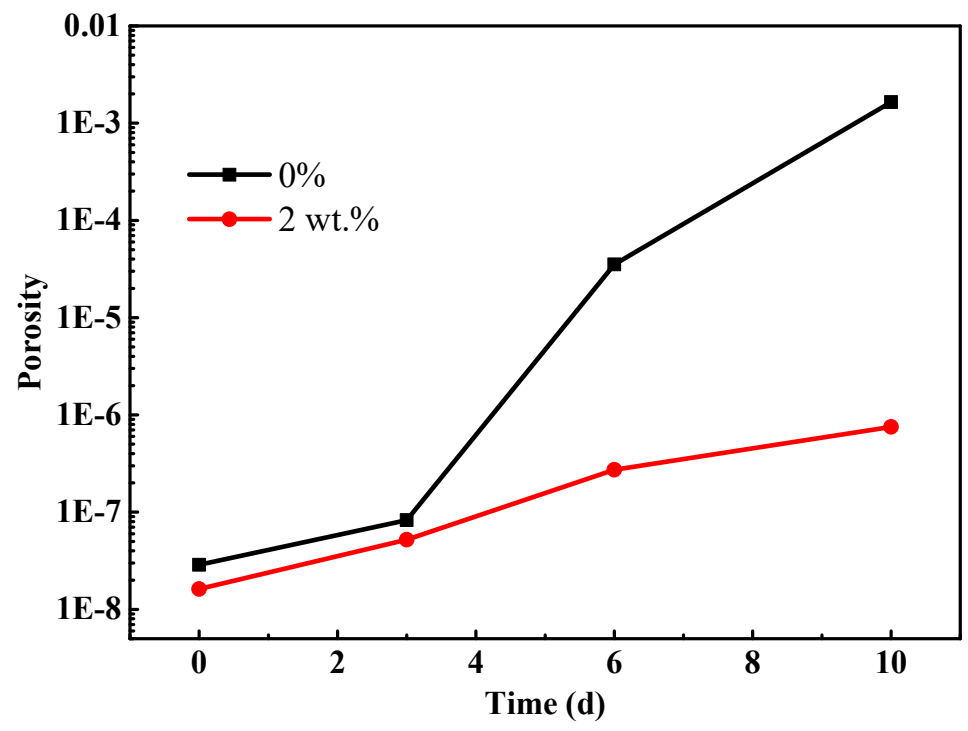

Figure 8. The change trend of coating porosity with the salt spray time.

\subsection{SKP Analysis}

Figure 9 shows the surface Kelvin potential mapping of the coating at different stages of the salt spray test. Apparently, the surface potential of the scratch is lower than that of the nearby coating before the salt spray tests (Figure $9 a, b$ ). This is related to the release of electrons process. The coating displays an insulator characterization; thus, the electron escape process is very difficult and shows a higher surface potential. Moreover, Figure 9a shows that the potential difference between the coating and scratch is around $0.13 \mathrm{~V}$ for the sample without composite filler; while the waterborne polyurethane coating with $2 \mathrm{wt} \%$ filler shows a smaller value: $0.09 \mathrm{~V}$ (Figure $9 \mathrm{~b}$ ). It is mainly attributed to the enhancement of the electric conductivity due to the addition of carbon materials. According to the previously published literatures [32-34], the surface Kelvin potential has a linear relationship with the corrosion potential of the sample; thus, the change of the Kelvin potential can be used to examine the change law of the corrosion potential. Consequently, it can be speculated that the substrate metal of the waterborne polyurethane coating sample will suffer from more severe galvanic corrosion at the initial stage due to the higher potential difference [35]. The addition of a composites filler will improve the corrosion protection performance to some extent.

Figure $9 \mathrm{c}, \mathrm{d}$ is the surface potential distribution after $3 \mathrm{~d}$ of salt spray tests. It can be found that the surface potential of the scratch area increases. Especially for the sample without composite filler, the surface potential of the coating and scratches reverse. This is because under the salt spray environment, the substrate metal is corroded, and a lot of corrosion products are piled on the scratch area. In this situation, the electron release process at the scratch area becomes difficult, and thus, the surface potential rises. Compared with the coating with composite filler, the coating without filler undergoes more serious corrosion damage after $3 \mathrm{~d}$ of the salt spray experiment due to the higher corrosion potential difference; thus, the surface potential of the scratch area significantly enhances and caused the potential reversal phenomenon. In fact, this surface potential change further confirms the advantages of the composites filler for the improvement of corrosion protection performance, which is consistent with the EIS results. As the salt spray time extends, the corrosion extent of the metal at the scratch area is aggravated. In the meantime, the amount of the corrosion products increases and becomes compact, which hinders the release process of electrons and causes the surface potential of the scratch area to further increase (Figure 9e,f). 


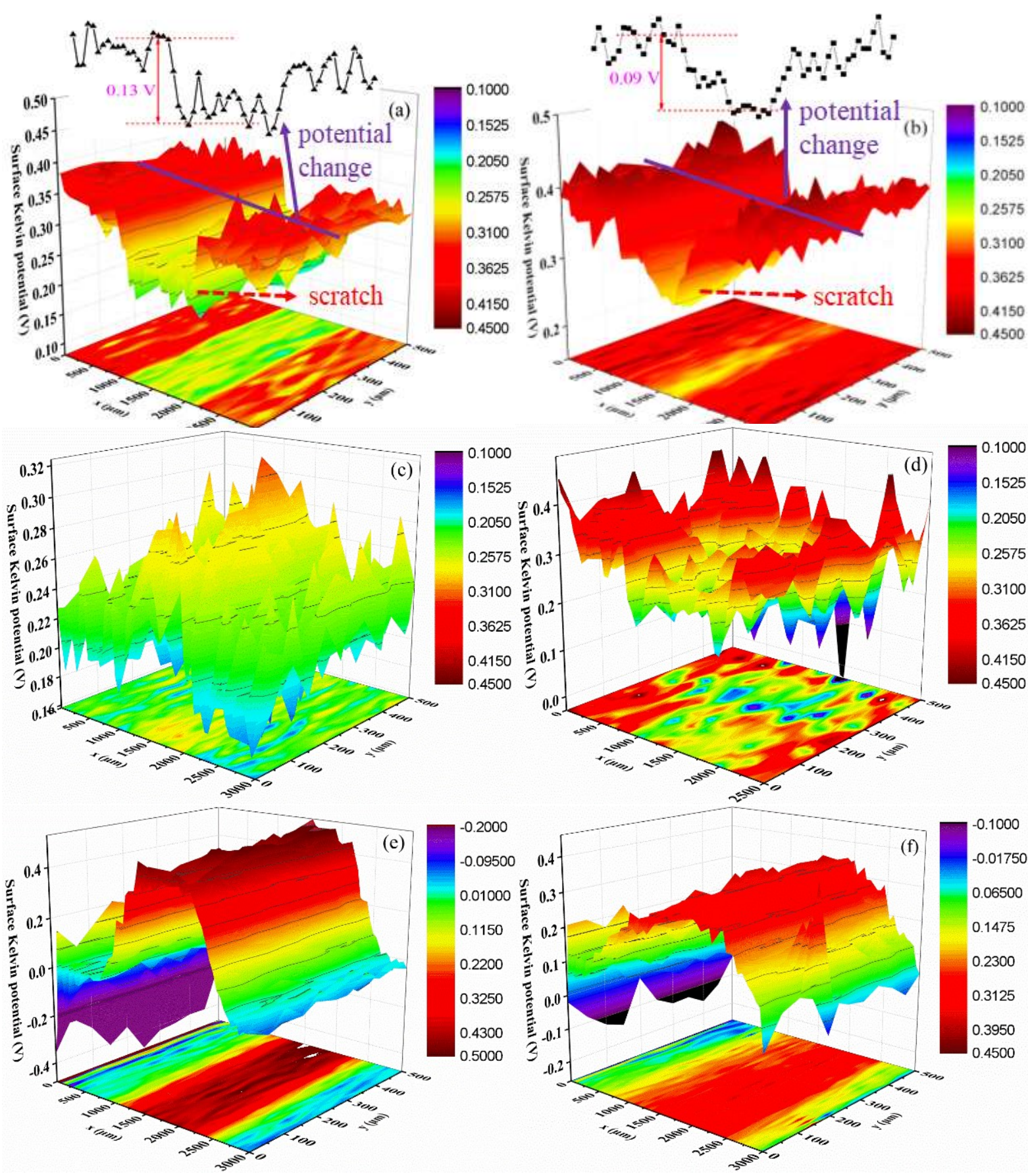

Figure 9. Surface Kelvin potential mapping of samples after salt spray tests with different periods, (a) $0 \%, 0 \mathrm{~d}$; (b) $2 \mathrm{wt} \%, 0 \mathrm{~d}$; (c) $0 \%, 3 \mathrm{~d}$; (d) $2 \mathrm{wt} \%, 3 \mathrm{~d}$; (e) 0\%, $10 \mathrm{~d}$; (f) $2 \mathrm{wt} \%, 10 \mathrm{~d}$.

\subsection{Protective Mechanism of the Composite Coating}

Based on the above analysis, it can be concluded that the corrosion resistance of the waterborne polyurethane coating could be enhanced by composite fillers, and the corresponding protective mechanism is depicted in Figure 10. During the curing process of coating, some pores are formed due to the evaporation of solvent. For the waterborne polyurethane coating, the chloride ions, water, and oxygen i.e., could readily penetrate into the coating and reach the interface between the coating and Q235 steel [36,37] due to its larger size pores and bad shielding property (Figure 10a). Then, the electrochemical reactions occur on the Q235 steel surface and cause severe corrosion. Thus, the waterborne polyurethane coating shows a weak protective action for the substrate metal. After adding 
$2 \mathrm{wt} \%$ composite fillers, these fillers with different sizes are dispersed in the coating and fill some initial coating pores, which promotes the coating compactness and thus decreases the penetration channel for the corrosive ions, as is shown in Figure 10b. Moreover, the addition of fillers could affect the penetration path of the electrolyte [38] and delay the time for the corrosive ions to arrive on the Q235 surface. Therefore, it can be concluded that the incorporation of proper carbon materials could not only improve the thermal conductivity of the coating but also enhance the validly of its anticorrosion performance in the simulated marine environment.
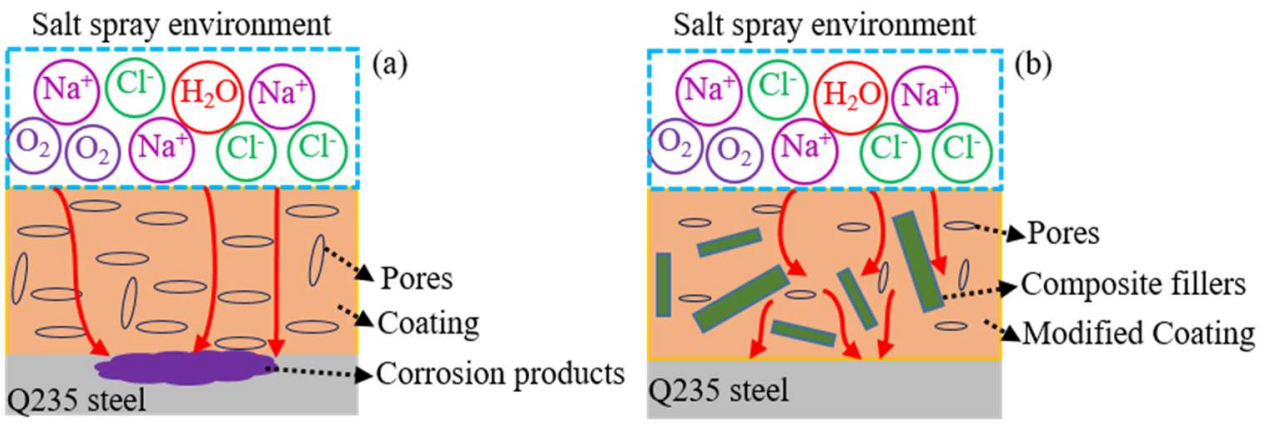

Figure 10. The protective mechanism of the composite coating on the substrate metal, (a) waterborne polyurethane coating; (b) modified composite coating.

\section{Conclusions}

In this paper, a waterborne polyurethane coating with high thermal conductivity is proposed, and then, its corrosion protection performance is studied through salt spray experiments, EIS measurements, and SKP tests. The results show that the addition of mixture fillers significantly improves the thermal conductivity of the coating. Especially for the modified coating with $2 \mathrm{wt} \%$ composite fillers, the thermal conductivity increases to $1.222 \mathrm{~W} \cdot \mathrm{m}^{-1} \cdot \mathrm{K}^{-1}$. In terms of corrosion resistance property, the waterborne polyurethane coating undergoes apparent corrosion damage, and a great number of rust spots occur on its surface after $6 \mathrm{~d}$ of salt spray tests. EIS measurement results also depict that the polarization resistance sharply decreases as the salt spray time increases. The polarization resistance decays to $3.24 \times 10^{3} \Omega \cdot \mathrm{cm}^{2}$ when the salt spray time reaches $10 \mathrm{~d}$, implying that the coating loses the protective effects on the substrate metal. However, for the modified coating, during the salt spray test, there is an absence of obvious corrosion phenomenon, and the polarization resistance is still as high as $1.31 \times 10^{7} \Omega \cdot \mathrm{cm}^{2}$ at the final stage. Overall, the incorporation of $2 \mathrm{wt} \%$ composite fillers markedly enhances the corrosion resistance property of waterborne polyurethane coating. This is mainly attributed to the more compact structure and more excellent shielding action to the electrolyte. The surface Kelvin potential results further confirm the advantageous effects of mixture fillers on the corrosion protective performance. The corresponding protective mechanism of the composite coating is also proposed in this work.

Author Contributions: P.Y. and J.M. conceived and designed the study; P.Y. performed the experiments and wrote the paper; R.L. and B.F. helped with drawing and analysis; K.X., J.G. and H.Z. reviewed the edited manuscript. All authors have read and agreed to the published version of the manuscript.

Funding: This work was supported by the Science and Technology project of State Grid Corporation of China (Study on performance evaluation and testing technology of environmentally friendly anti-corrosive coatings for transmission and distribution equipment, 5200-202119092A-0-0-00).

Institutional Review Board Statement: Not applicable.

Informed Consent Statement: Not applicable.

Data Availability Statement: The raw/processed data required to reproduce these findings cannot be shared at this time due to legal or ethical reasons. 
Acknowledgments: We thank the staff at the same laboratory in the China Electric Power Research Institute.

Conflicts of Interest: The authors declare no conflict of interest.

\section{References}

1. Wu, G.L.; Zhong, Y.; Ren, X.; Hao, J.; Wang, Q.; Wang, X.P. Atmospheric Corrosion State Evaluation Based on Surface Corrosion Morphology for Electrical Metal Frame Equipment in Chongqing Power Grid. Key Eng. Mater. 2019, 815, 89-95. [CrossRef]

2. Li, N.; Jiang, Q.; Wang, F.S.; Xie, J.; Li, Y.; Li, J.; Wu, S. Emission behavior, environmental impact and priority-controlled pollutants assessment of volatile organic compounds (VOCs) during asphalt pavement construction based on laboratory experiment. J. Hazard. Mater. 2020, 398, 122904-122913. [CrossRef] [PubMed]

3. Liu, S.; Gu, L.; Zhao, H.C.; Chen, J.; Yu, H. Corrosion Resistance of Graphene-Reinforced Waterborne Epoxy Coatings. J. Mater. Sci. Technol. 2016, 32, 425-431. [CrossRef]

4. He, Y.J.; Boluk, Y.; Pan, J.S.; Ahniyaz, A.; Deltin, T.; Claesson, P.M. Corrosion protective properties of cellulose nanocrystals reinforced waterborne acrylate-based composite coating. Corros. Sci. 2019, 155, 186-194. [CrossRef]

5. Yang, Z.F.; Ruan, J.J.; Huang, D.C.; Du, Z.Y.; Tang, L.Z.; Zhou, T.T. Calculation of hot spot temperature of transformer bushing considering current fluctuation. IEEE Access 2019, 7, 120441-120448. [CrossRef]

6. Liu, G.; Zheng, Z.; Yuan, D.W.; Li, L.; Wu, W. Simulation of Fluid-Thermal Field in Oil-Immersed Transformer Winding Based on Dimensionless Least-Squares and Upwind Finite Element Method. Energies 2018, 11, 2357. [CrossRef]

7. Milad, A.; Mehdi, A.; Rashid, M. Heat Analysis of the Power Transformer Bushings in the Transient and Steady States Considering the Load Variations. Appl. Therm. Eng. 2017, 121, 999-1010.

8. Marcos, V.; Gonçalves, D.R.; Michel, B.H. Power Transformers Thermal Modeling using an Enhanced Set-Membership Multivariable Gaussian Evolving Fuzzy System. Electr. Pow. Syst. Res. 2021, 194, 107088-107099.

9. Wang, F.Z.; Lawrence, T.D.; Yan, Q.; Huang, Z.X. Mechanical properties and thermal conductivity of graphene nanoplatelet/epoxy composites. J. Mater. Sci. 2015, 50, 1082-1093. [CrossRef]

10. Ma, H.Q.; Gao, B.; Wang, M.Y.; Yuan, Z.Y.; Shen, J.B.; Zhao, J.Q.; Feng, Y.K. Strategies for enhancing thermal conductivity of polymer-based thermal interface materials: A review. J. Mater. Sci. 2021, 56, 1064-1086. [CrossRef]

11. Burger, N.; Laachachi, A.; Ferriol, M.; Lutzc, M.; Toniazzo, V.; Rucha, D. Review of thermal conductivity in composites: Mechanisms, parameters and theory. Prog. Polym. Sci. 2016, 61, 1-28. [CrossRef]

12. Kochetov, R.; Andritsch, T.; Lafont, U.; Morshuis, P.H.F.; Picken, S.J.; Smit, J.J. Thermal behaviour of epoxy resin filled with high thermal conductivity nanopowders. In Proceedings of the 2009 IEEE Electrical Insulation Conference, Montréal, QC, Canada, 31 May-3 June 2009; Institute of Electrical and Electronics Engineers (IEEE): Piscataway, NJ, USA, 2009; pp. $524-528$.

13. Bian, W.C.; Yao, T.; Chen, M.; Zhang, C.; Shao, T.; Yang, Y. The Synergistic Effects of the Micro-BN and $\mathrm{NanoAl}_{2} \mathrm{O}_{3}$ in Micro-nano Composites on Enhancing the Thermal Conductivity for Insulating Epoxy Resin. Compos. Sci. Technol. 2018, 168, 420-428. [CrossRef]

14. Santosh, K.Y.; Jae, W.C. Functionalized graphene nanoplatelets for enhanced mechanical and thermal properties of polyurethane nanocomposites. Appl. Surf. Sci. 2013, 266, 360-367.

15. Shi, Q.; Zhu, A.P. Interface regulation of graphene/carbon nanotube on the thermal conductivity and anticorrosion performance of their nanocomposite. Prog. Org. Coat. 2020, 140, 105480-105486. [CrossRef]

16. Song, H.F.; Kang, F.Y. Recent Progress on Thermal Conduction of Graphene. Acta Phys. Chim. Sin. 2021, 37, 2101013-2101028 [CrossRef]

17. Sung, H.S.; Kwang, H.P.; Bo, H.M.; Yong, W.C.; Gwang, H.J.; Dong, J.L.; Byung, S.K.; Kyung, W.P.; Seokwoo, J. Enhanced Thermal Conductivity of Epoxy-Graphene Composites by Using Non-Oxidized Graphene Flakes with Non-Covalent Functionalization. Adv. Mater. 2013, 25, 732-737. [CrossRef]

18. Zhu, D.H.; Qi, Y.; Yu, W.; Chen, L.F.; Wang, M.Z.; Xie, H.Q. Enhanced Thermal Conductivity for Graphene Nanoplatelets/Epoxy Resin Composites. J. Thermal Sci. Eng. Appl. 2018, 10, 11011-11015. [CrossRef]

19. Biedenkopf, P.; Spiegel, M.; Grabke, H.J. High temperature corrosion of low and high alloy steels under molten carbonate fuel cell conditions. Mater. Corros. 1997, 48, 477-488. [CrossRef]

20. Zhao, Z.H.; Guo, L.; Feng, L.; Lu, H.; Xu, Y.; Wang, J.N.; Xiang, B.; Zou, X.F. Polydopamine functionalized graphene oxide nanocomposites reinforced the corrosion protection and adhesion properties of waterborne polyurethane coatings. Eur. Polym. J. 2019, 120, 109249-109261. [CrossRef]

21. Liu, Z.; Li, X.; Cheng, Y. Understand the occurrence of pitting corrosion of pipeline carbon steel under cathodic polarization Electrochim. Acta 2012, 60, 259-263. [CrossRef]

22. Hinderliter, B.R.; Croll, S.G.; Tallma, D.E.; Su, Q.; Bierwagen, G.P. Interpretation of EIS data from accelerated exposure of coated metals based on modeling of coating physical properties. Electrochim. Acta 2006, 51, 4505-4515. [CrossRef]

23. Fu, T.; Tang, X.B.; Cai, Z.K.; Zuo, Y.; Tang, Y.M.; Zhao, X.H. Correlation research of phase angle variation and coating performance by means of Pearson's correlation coefficient. Prog. Org. Coat. 2020, 139, 105459-105467. [CrossRef]

24. Zhang, F.Y.; Liu, W.Q.; Liang, L.Y.; Wang, S.; Shi, H.Y.; Xie, Y.K.; Yang, M.P.; Pi, K. The effect of functional graphene oxide nanoparticles on corrosion resistance of waterborne polyurethane. Colloid. Surface A 2020, 591, 124565-124574. [CrossRef] 
25. Ye, Y.W.; Zhang, D.W.; Liu, T.; Liu, Z.Y.; Liu, W.; Pu, J.B.; Chen, H.; Zhao, H.C.; Li, X.G. Improvement of anticorrosion ability of epoxy matrix in simulate marine environment by filled with superhydrophobic POSS-GO nanosheets. J. Hazard. Mater. 2019, 364, 244-255. [CrossRef] [PubMed]

26. Zhou, S.G.; Wu, Y.M.; Zhao, W.J.; Yu, J.J.; Jiang, F.W.; Ma, L.Q. Comparative corrosion resistance of graphene sheets with different structures in waterborne epoxy coatings. Colloid. Surf. A 2018, 556, 273-283. [CrossRef]

27. Shi, P.; Niu, B.; Shanshan, E.; Chen, Y.; Li, Q. Preparation and characterization of PLA coating and PLA/MAO composite coatings on AZ31 magnesium alloy for improvement of corrosion resistance. Surf. Coat. Technol. 2015, 262, 26-32. [CrossRef]

28. Yi, P.; Zhu, L.J.; Dong, C.F.; Xiao, K. Corrosion and interfacial contact resistance of 316L stainless steel coated with magnetron sputtered $\mathrm{ZrN}$ and TiN in the simulated cathodic environment of a proton-exchange membrane fuel cell. Surf. Coat. Technol. 2019, 363, 198-202. [CrossRef]

29. Ye, Y.W.; Zhang, D.W.; Liu, T. Superior corrosion resistance and self-healable epoxy coating pigmented with silanzied trianilineintercalated graphene. Carbon 2019, 142, 164-176. [CrossRef]

30. Armstrong, R.D.; Wright, D. Polymer protective coatings-The distinction between coating porosity and the wetted metal area. Electrochim. Acta 1993, 38, 1799-1801. [CrossRef]

31. Zhu, Y.F.; Xiong, J.P.; Tang, Y.M.; Zuo, Y. EIS study on failure process of two polyurethane composite coatings. Prog. Org. Coat. 2010, 69, 7-11. [CrossRef]

32. Yi, P.; Xiao, K.; Ding, K.K.; Dong, C.F.; Li, X.G. Surface failure mechanism of PCB-ENIG in typical outdoor atmospheric environments. Mater. Res. Bull. 2017, 91, 179-188. [CrossRef]

33. Yi, P.; Xiao, K.; Dong, C.F.; Zou, S.W.; Li, X.G. Effects of mould on electrochemical migration behaviour of immersion silver finished printed circuit board. Bioelectrochemistry 2018, 119, 203-210. [CrossRef] [PubMed]

34. Ding, K.K.; Xiao, K.; Dong, C.F.; Zou, S.W.; Yi, P.; Li, X.G. Initial Corrosion Behavior and Mechanism of PCB-HASL in Typical Outdoor Environments in China. J. Electron. Mater. 2015, 44, 4405-4417. [CrossRef]

35. Reddy, B.; Sykes, J.M. Degradation of organic coatings in a corrosive environment: A study by scanning Kelvin probe and scanning acoustic microscope. Prog. Org. Coat. 2005, 52, 280-287. [CrossRef]

36. Wang, L.D.; Wu, W.D.; Sun, W.; Yang, Z.Q.; Wang, S.L.; Liu, G.C. Partially dehydrated zinc hydroxide sulfate nanoplates reinforced coating for corrosion protection. Chem. Eng. J. 2019, 373, 8-22. [CrossRef]

37. Liu, T.; Wei, J.Y.; Ma, L.W.; Liu, S.; Zhang, D.W.; Zhao, H.C. Effect of polyaniline-based plate on the anticorrosion performance of epoxy coating. Prog. Org. Coat. 2021, 151, 106109-106119. [CrossRef]

38. Nurul, H.O.; Mokhtar, C.I.; Mazli, M.; Nabihah, S.; Kok, E.K.; Rafida, A.J. Graphene-based polymer nanocomposites as barrier coatings for corrosion protection. Prog. Org. Coat. 2019, 135, 82-99. 